\title{
Mobilidade e violência no Rio de Janeiro: o papel das redes sociais digitais
}

\author{
Mobility and violence in Rio de Janeiro: The role of digital social \\ networks
}

\section{Bianca Fernandes Antunes}

Bianca Fernandes Antunes é jornalista formada pela Faculdade Hélio Alonso (FACHA). Mestre em Comunicação pela UERJ, possui MBA em Marketing pela Coppead/UFRJ e pós em Comunicação e Saúde pela Fiocruz. Atualmente é doutoranda no Programa de Pós-Graduação da Universidade do Estado do Rio de Janeiro (PPGCOM-UERJ).

\section{Leticia Cantarela Matheus}

Leticia Cantarela Matheus é bolsista Prociência, doutora em Comunicação pela Universidade Federal Fluminense (UFF) e professora do Programa de PósGraduação da Universidade do Estado do Rio de Janeiro (PPGCOM-UERJ).

\section{RESUMO}

0 artigo discute de que forma a fanpage do Facebook "Onde Tem Tiroteio" (OTTRJ) possibilita imaginar uma geografia do crime na cidade do Rio de Janeiro. 0 objetivo é explorar as tensões simbólicas em torno de um conjunto de interações nesta página capaz de mediar, para seus usuários, a experiência do Rio e observar o comportamento desses usuários em relação à cidade a partir desta que seria uma mídia locativa analógica (Lemos, 2009). Para testar essas duas hipóteses, acompanhamos a fanpage e analisamos, do ponto de vista discursivo, um conjunto de comentários sobre como os moradores justificam sua relação com a OTT-RJ e com a cidade. 0 recorte, de uma pesquisa maior em andamento, contempla 50 comentários a 12 posts publicados no dia 16 de fevereiro de 2018, dia da intervenção federal no estado, para conter a violência.

PALAVRAS-CHAVE: Mídia; Violência; Mídia locativa analógica; Geografia; Facebook.

\section{ABSTRACT}

This paper discusses how the Facebook fanpage "OTT-RJ" ("Where there are crossfires?") allow us to imagine a geography of crime in Rio de Janeiro city. The aim is to explore the symbolic tensions surrounding a set of interactions that take place on this platform, which mediates Rio's experience, as well as to observe the users behavior regarding the city whereas from the perspective of this analogical

Dossiê Feminismos vitais - https://revistaecopos.eco.ufrj.br/

ISSN 2175-8689 - v. 24, n. 1, 2021

DOI: 10.29146/ecopos.v24i1.27624 
locative media (Lemos, 2009). In order to test both hypotheses, we followed the fanpage and analyzed, from a discursive point of view, a set of comments about how people justify their relationship with OTT-RJ and with the city. The sample belongs to larger research in progress and includes 50 comments on 12 posts on February 16th 2018, the inauguration day of the federal intervention in Rio de Janeiro's State, in order to restrain criminality.

KEYWORDS: Media; Violence; Analogical locative media; Geography; Facebook.

Submetido em 18 de Setembro de 2020

Aceito em 03 de Dezembro de 2020

\section{Introdução}

Em 2010, foi criado, na cidade do Rio de Janeiro, o Centro de Operações Rio (COR), uma central de monitoramento que gera, analisa e divulga informações sobre mobilidade urbana, reunindo 30 órgãos públicos. Embora responsável por anunciar interdições de trânsito, incluindo aquelas provocadas por operações policiais, o enfoque do COR não é informar o cidadão sobre a violência armada. Para tentar suprir essa demanda, houve uma explosão de ferramentas digitais, indo desde grupos privados e comunidades em sites de redes sociais, grupos no WhatsApp e até aplicativos de celular, com o objetivo de alertar a população sobre tiroteios. O hábito provavelmente começou em 2008, quando alguns motoristas passaram a alertar uns aos outros sobre evitar a blitz da Lei Seca. Naquele mesmo ano, enquanto o carioca fugia dos "bafômetros", a cidade recebia as Unidades de Polícia Pacificadora (UPPs), projeto de segurança que consistia em instalar "postos avançados" de batalhões da Polícia Militar dentro das favelas, com nova proposta de policiamento comunitário. Esses acontecimentos aparentemente não correlatos teriam seus efeitos entrelaçados em novas práticas digitais, resultando no boom de mídias locativas (Lemos, 2009) voltadas para a segurança. Enquanto os apps são 
obviamente mídias locativas, os sites de redes sociais (Recuero, 2009) podem ou não ser usados desta forma. Neste artigo, estudamos a fanpage do Facebook "Onde Tem Tiroteio" (OTT-RJ) que, como o nome diz, serve ainda hoje para avisar os moradores sobre a ocorrência de tiroteios e o risco de balas perdidas. ${ }^{3}$ Lançada em janeiro de 2016, a OTT-RJ passou, mais tarde, a formar uma rede de plataformas (Twitter, YouTube, Instagram, Telegram, WhatsApp e Zello). Em 2019, virou aplicativo.

O fenômeno, que pode parecer inusitado ou exagerado, justifica-se em uma cidade em que o medo da bala perdida ocupa lugar central na experiência urbana, seja na prática ou imaginariamente (Matheus, 2011), e em um estado cujo índice de letalidade violenta chegou a 6.714 vítimas em 2018 (ISP, 2021), embora esta taxa tenha caído 7\% em relação a 2017. A Região Metropolitana do Rio teve média de 20 tiroteios por dia em 2019 (Fogo Cruzado, Relatório 2020, online). Foram detectados 7.365 tiroteios/disparos de arma de fogo naquele ano, número 24\% menor que em 2018, quando houve uma intervenção federal específica para a área de Segurança Pública (Decreto federal n. 2988, de 16 de fevereiro de 2018).

Este artigo apresenta uma reflexão sobre esse cenário de digitalização da violência, tomando como referencial empírico a OTT-RJ no Facebook. Há, simultaneamente, dois eixos reflexivos, não necessariamente satisfeitos e que se mantém abertos à investigação. 0 primeiro leva à opção pela fanpage, devido à sua função ainda intermediária em um mundo digital - ainda não totalmente locativo e que inclui tecnologias de monitoramento. Se aceitamos que um site de rede social possa funcionar como solução intermediária em direção à geolocalização, tal limitação tecnológica foi superada dois anos mais tarde, quando a OTT-RJ se tornou aplicativo. 0 segundo eixo reflexivo diz respeito à capacidade de o cidadão

30 nome lembra ainda a sigla para "over-the-top", termo usado para designar a tecnologia que permite transmissões em streaming.

Dossiê Feminismos vitais - https://revistaecopos.eco.ufrj.br/

ISSN 2175-8689 - v. 24, n. 1, 2021

DOI: 10.29146/ecopos.v24i1.27624 
experimentar uma cidade imaginada a partir dessa territorialidade mediada pela OTT-RJ.

Para ancorar essas reflexões, realizamos um recorte temático acerca da percepção da violência na cidade do Rio de Janeiro no dia 16 de fevereiro de 2018, data da intervenção federal, e ano da extinção do projeto das UPPs, que havia durado 10 anos. Com a intervenção, o Comando Militar do Leste assumiu as Polícias Civil e Militar e o Corpo de Bombeiros, para "pôr termo a grave comprometimento da ordem pública no Estado do Rio de Janeiro" (Decreto 9.288, art. $1, \S 2$ ) e o projeto das UPPs foi encerrado.

Construímos um corpus com 50 comentários a 12 posts feitos naquele dia 16 e comentados nas 24 horas seguintes. 0 objetivo foi perceber as relações que os usuários relatavam ter com a cidade e com a própria OTT-RJ. Como relatavam sua experiência com a violência e com a cidade? Além da interpretação dos comentários, foi realizada uma etnografia para internet (Fragoso et al., 2011), a partir da observação da fanpage. Para compreender melhor a OTT-RJ, também entrevistamos três de seus quatro administradores.

\section{Mídias locativas e territórios informacionais}

Inaugurado em 2010, o COR ${ }^{4}$ foi uma das iniciativas para a preparação do Rio para a série de megaeventos que a cidade recebeu, tais como a Jornada Mundial da Juventude (2013), a Copa do Mundo (2014) e as Olimpíadas, em 2016, uma vez que permitiria monitorar e gerir o fluxo de comitiva, turistas e moradores circulando em diferentes transportes e direções. Do mesmo modo, as UPPs foram implantadas em 2008 com o intuito de preparar a cidade para esses megaeventos,

4 Centro de Operações Rio: http://cor.rio/

Dossiê Feminismos vitais - https://revistaecopos.eco.ufrj.br/

ISSN 2175-8689 - v. 24, n. 1, 2021

DOI: 10.29146/ecopos.v24i1.27624 
de modo a promover a segurança dos turistas, ao tentar reduzir a criminalidade ${ }^{5}$. Passados os megaeventos, as UPPs foram ressignificadas como fracasso pelos mesmos jornais que tanto as celebraram, sendo substituídas então pela Intervenção Federal.

Para ajudar moradores e agentes públicos, o COR publica informações sobre mobilidade urbana no site e emite três boletins diários, utilizando o Twitter e o Facebook. Suas temáticas são principalmente trânsito e previsão do tempo, uma vez que temporais, no Rio de Janeiro, também implicam perda de mobilidade. Porém, as notícias sobre violência aparecem apenas tangencialmente, se for o caso de possíveis interdições em função de alguma operação policial. Pode-se dizer que o conceito que governa o COR é a gestão de risco relativo majoritariamente ao impacto negativo na mobilidade urbana pelo risco de engarrafamento, pelo risco de tempestades e alagamentos, e pelo risco de obstruções por operações policiais. Porém o risco de morrer em um tiroteio não é o enfoque do COR. Tanto o risco de morte não é o enfoque do COR que, em 2017, ao lançar o aplicativo Alerta Rio, com recurso colaborativo, o tema são as condições climáticas, tais como visibilidade e condições de aderência das pistas.

Em julho de 2019, enquanto o COR possuía 422 mil seguidores no Facebook e 653.7 mil no Twitter, a página da OTT-RJ tinha 705.335 seguidores no Facebook ${ }^{6}$, 145.082 no Twitter7, 135 mil no Instagram e 15.300 inscritos no canal do YouTube. Ou seja, no momento em que virou aplicativo, a OTT-RJ já possuía uma adesão muito maior do que o COR, o dobro do número de exemplares impressos diários e de assinaturas digitais do jornal 0 Globo, por exemplo, em 2018: 315.044 (Rosa, 0 Globo, 25 de janeiro de 2019, online). Somando todas as plataformas, a rede OTT afirma atender a 4,7 milhões de pessoas, "com informes em tempo real, onde mais

5 Nos primeiros anos do projeto de fato alguns índices de criminalidade caíram, porém, com o passar do tempo, as críticas foram aumentando e os resultados positivos, caindo.

$6 \mathrm{https}$ //www.facebook.com/OTTRJ

7 Twitter: @RJ_OTT

Dossiê Feminismos vitais - https://revistaecopos.eco.ufrj.br/

ISSN 2175-8689 - v. 24, n. 1, 2021

DOI: 10.29146/ecopos.v24i1.27624 
da metade acessa nossa rede por smartphones e tablets". Esse número inclui os 500 mil usuários que, segundo o aplicativo, "tem a missão de salvar de balas perdidas, arrastões e de falsas blitz que atormentam o Brasil" (Quem somos, OTT, online $)^{8}$.

A adesão ao app da OTT-RJ também é maior que a de um aplicativo concorrente, o Fogo Cruzado9 , que possui 200 mil usuários. Criado pelo Instituto Update, a plataforma possui o apoio de universidades nacionais e internacionais, das fundações Oak Foundation e ShuttleWorth Foundation, do Ministério Público do Rio de Janeiro, da Defensoria Pública do Rio de Janeiro, entre entidades civis, e publica relatórios de dados sobre crimes violentos periodicamente. Segundo a plataforma, que assim como a OTT possui uma fanpage, a margem de rejeição de avisos é de $16 \%$ de notificações inverídicas. A questão da mobilidade também é central para esta plataforma, cujo site informa que um dos objetivos é chamar a atenção para crimes que podem eventualmente não ter registro, mas que causam impacto no trânsito (Fogo Cruzado, Perguntas frequentes, online).

Os dois aplicativos permitem configurar a abrangência do raio do GPS. 0 Fogo Cruzado começa em 4km, podendo alcançar toda a Região Metropolitana do Rio. 0 OTT-RJ chega a $300 \mathrm{~km}$ de raio. Em 2018, o aplicativo da OTT chegou a São Paulo, mas, no Facebook, também já existia uma fanpage relativa ao Espírito Santo. Isto é, as diferentes plataformas digitais se mostram bastante complementares para formar a rede OTT.

Fundada em janeiro de 2016 por quatro amigos preocupados com o crescimento descontrolado da violência no Brasil, a OTT-Brasil tem como principal missão retirar todos os cidadãos das rotas dos arrastões, das falsas blitz e das balas perdidas, com informações que são colhidas, analisadas e divulgadas num curtíssimo espaço de tempo.

8 https://www.ondetemtiroteio.com.br/

9 https://fogocruzado.org.br/sobre/

Dossiê Feminismos vitais - https://revistaecopos.eco.ufrj.br/

ISSN 2175-8689 - v. 24, n. 1, 2021

DOI: 10.29146/ecopos.v24i1.27624 
O conceito SP 4.0, Segurança Pública 4.0, que norteia a nossa dinâmica de trabalho, se baseia na segurança feita do cidadão para o cidadão (C2C), uma espécie de segurança "Smart", onde cada cidadão atualiza, em tempo real, a segurança em seu entorno, ajudando a ele e a todos os outros participantes de nossa rede dinâmica de informações.

Hoje, presente em todas as redes sociais, conseguimos atingir mais de 4,7 milhões de pessoas com nossos informes em tempo real, onde mais da metade acessa nossa rede por smartphones e tablets. No entanto, a cada dia trabalhamos para que nossa rede aumente e abranja todo o mundo e assim, ajudando mais pessoas (OTT-Brasil, Quem Somos, online).

Um dos criadores da rede, Benito Quintanilha, contou em entrevista a uma das autoras que usava seu perfil pessoal no Facebook para postar alertas sobre tiroteios na cidade. Pela quantidade de seguidores que acabou ganhando, sentiu necessidade de criar uma página exclusiva para o tema, de modo a aumentar o alcance dessas publicações. 0 enfoque era na publicação de informações, fotos e vídeos sobre tiroteios enviados pelos próprios moradores do Rio, de forma colaborativa.

Vi na televisão um caso de bala perdida no Complexo do Alemão, nos meados de 2015. Queria que as pessoas não tivessem a mesma experiência. Iniciei a página com alertas e foi ganhando uma proporção e vi a necessidade de continuar postando. Toda violência choca. Afinal, estamos em um estado que não está em guerra oficialmente, mas que tem números de violência de uma região em guerra. Não era para ser assim, mas infelizmente é (Quintanilha, 2019, por telefone).

Uma equipe de cerca de 400 colaboradores assíduos confirma ou não os alertas. Além da fanpage, da qual falaremos adiante, a OTT-RJ possui uma rede de 700 grupos no WhatsApp, sendo que cada grupo comporta 256 integrantes. Segundo seus administradores, o objetivo é formar a maior rede colaborativa de segurança do Brasil.

No início, a OTT-RJ divulgava apenas informações sobre tiroteio, somando mais tarde avisos de arrastões e de interdições. Segundo Quintanilha (2019), como 
o objetivo é que o cidadão saia ileso de um trajeto, são publicados apenas alertas para que o morador saia do local o mais rápido possível, sem detalhes sobre o ocorrido. Nesse sentido, a fanpage não substitui o trabalho jornalístico. Enquanto serviço de alerta, entretanto, é preciso questionar sua eficácia, uma vez que dificilmente um site de rede social pode competir com a velocidade de aplicativo de alerta geolocalizado. Provavelmente, até que o usuário decida entrar no Facebook, ou morreu ou o tiroteio passou. Nesse sentido, a fanpage parece muito mais repercutir do que, de fato, alertar para o risco iminente de ser alvejado, tarefa para a qual o aplicativo é mais indicado.

Segundo Quintanilha (2019), a rede OTT-RJ recebe mais de cem informes de tiros e de conflitos bélicos diariamente. Como eles prezam pela veracidade do que é publicado, são postadas apenas cerca de 15 a 20 ocorrências por dia, que é a média de crimes confirmados pela rede. Nem sempre é possível verificar se todos os incidentes são verdadeiros. "Às vezes, essa confirmação demora a chegar. Então, não postamos porque, como nossa ideia é evitar que a pessoa seja alvo da violência, o alerta tem que ser dado no momento que o incidente estiver acontecendo", explica. A atualidade da informação, portanto, é vital. 0 interessante aqui é a apropriação do mesmo tipo de procedimento utilizado por jornalistas: a confirmação da informação e o valor da urgência a respeito de acontecimento novo, de mudanças recentes em alguma situação nova ou uma novidade na cidade.

O conteúdo é incluído no Facebook somente pelos quatro administradores. Os tiroteios não são noticiados apenas quando estão em andamento ou depois de acontecerem. Também são postados alertas de moradores que julgam haver iminência de tiroteios, geralmente, ligados a operações policiais. Esses dados são confirmados pelas pessoas que fazem parte dos grupos de WhatsApp e, principalmente, por moradores dos bairros atingidos. 
A partir de 20 de julho de 2019, essa dinâmica de publicação mudaria no aplicativo, permitindo a publicação direta de avisos de crimes pelos colaboradores. As contas nos sites de rede social, entre eles o Facebook, mudariam seu "perfil editorial", ficando limitados a informações de utilidade pública, tais como desaparecimento de pessoas, fuga de animais, perda de documento e roubo de automóveis. Essa migração de plataforma e a mudança “editorial” das contas nos sites de redes sociais foi vista com estranheza pelos seguidores da OTT, que reclamaram. Além disso, o fato de os seguidores só conseguirem ter acesso à informação completa pelo app também gerou insatisfação e, por isso, em 2020, os perfis nas redes sociais voltaram a ser alimentados com o mesmo conteúdo do aplicativo.

O caso da rede OTT em suas múltiplas plataformas e as demandas dos moradores do Rio permitem refletir sobre os limites da tecnologia e sobre como os usuários são capazes de dela se apropriar para usos que não estão inscritos, $a$ priori, naquela mídia. Segundo Lemos (2009), o que caracteriza as mídias locativas é que elas trabalham informações vinculadas a certos lugares, neste caso, obviamente, a cidade do Rio. Em essência, essas mídias estão ligadas à mobilidade, ou à portabilidade, isto é, são processos informacionais e equipamentos capazes de funcionar em deslocamento, ligado a uma rede de internet seja da companhia telefônica seja de um wi-fi qualquer. Mas, como vimos, a primeira plataforma onde a OTT-RJ habitou foi uma mídia estática: o Facebook.

Se tomarmos a cidade como um espaço onde se dão relações sociais, esse território é desde já mediado por tecnologias digitais ${ }^{10}$. Então que tipo particular

10 Todo espaço geográfico é socialmente construído. A opção pelos conceitos "território" ou "lugar" diz respeito, na Geografia, à opção teórico-metodológica: o primeiro acentua as relações de poder e o segundo a dotação de sentido (Souza, 2008, p. 80). Como, para a Comunicação, não existe sentido fora de disputas de poder, tal distinção se faz irrelevante. Para esta pesquisa, adotamos, então, o conceito de território, uma vez que, ao tratarmos de mídia, violência e medo, estamos obviamente falando de política.

Dossiê Feminismos vitais - https://revistaecopos.eco.ufrj.br/

ISSN 2175-8689 - v. 24, n. 1, 2021

DOI: 10.29146/ecopos.v24i1.27624 
de "digitalização" da cidade a fanpage da OTT-RJ é capaz de realizar? Enquanto o COR e projetos de smart cities traduzem informações sobre o espaço urbano em códigos manipuláveis, na fanpage da OTT-RJ, os dados sobre os tiroteios se baseiam exclusivamente em relatos feitos pelos usuários do Facebook e outras interações do tipo "curti" ou "compartilhei". Mas os metadados que essas interações possam ter gerado, se é que dizem algo sobre a cidade, não ajudam na construção de um mapa digital, muito menos "inteligente". A rigor, portanto, a fanpage OTT-RJ poderia ser definida como uma mídia locativa analógica (Lemos, 2009).

Embora o Facebook tenha recurso de geolocalização, o usuário pode mentir sobre ter estado no lugar x ou y e mentir a data. Essa geolocalização serve apenas para que o usuário faça buscas e marcações ativamente, basicamente pelo histórico de navegação, mas não permite que ele seja localizado pelo Facebook enquanto se movimenta, supondo que o usuário abra o site no aparelho celular. Por isso, a rigor, não se prestaria ao serviço de alerta. A fanpage também está longe de fazer parte da infraestrutura urbana, critério necessário para se falar em "smart city" (Oliveira; Castro, 2019). Parece que sequer o COR poderia ser assim classificado, pois não é automatizado e não trabalha em escala. Sua geração de dados é simplesmente por câmeras de monitoramento e por relatos das equipes da Prefeitura que estão na rua. Até onde se sabe, não há sensores espalhados pela cidade nem gestão por Big Data. Do mesmo modo, as informações sobre mobilidade disponíveis na fanpage OTT-RJ não são automáticas, não são baseadas em Big Data, ou seja, não são tão "smart" assim. Então, por que, durante três anos, ela foi capaz de servir - se é que serviu - como importante etapa na digitalização do território, ajudando o carioca a escapar de tiroteios e, ao mesmo tempo, lidando com o medo?

Embora a fanpage não seja um aplicativo de GPS, como dito anteriormente, um dos modos de interação mais prevalentes é que os usuários se marcam (tags), 
com o intuito de alertar amigos e parentes sobre a ocorrência de tiroteios ou para saber se estão bem. É evidente que este movimento é lento. Até a equipe da OTT-RJ conferir as informações, publicar o post e o usuário lembrar de entrar no Facebook pode ser tarde demais se ele estiver passando por uma área conflagrada. Isso não significa que o usuário não verifique a página da OTT-RJ antes de sair de casa ou do trabalho11, "geolocalizando-se" mentalmente, isto é, sem uma representação visual de um mapa digital ${ }^{12}$.

Há uma série de críticas à ideia de smart cities: a ilusão de neutralidade dos dados, a despolitização das decisões públicas, a ilusão de poder resolver boa parte dos problemas urbanos com soluções tecnológicas e o problema da invasão de privacidade, ao usar dados dos cidadãos. Além disso, há que se pensar na questão da mercantilização do fluxo dos cidadãos, transformado agora em dados (LuqueAyala, 2019). Nesse sentido, tanto a mobilidade quanto sua contingência podem ser "datificadas" e comercializadas, isto é, os metadados gerados por essas informações de caráter digital poderiam gerar lucros. Igualmente, o medo da violência armada permite a capitalização de toda uma indústria da segurança privada e da auto-segregação (Souza, 2008), tal como mostrou Freitas (2010) em relação a shopping centers e condomínios fechados, sobretudo no bairro da Barra da Tijuca. Para Souza (2008), "tanto a formação de enclaves territoriais criminosos quanto a proliferação de 'condomínios exclusivos' vão enfraquecendo a vida pública" (p. 84), logo, a cidadania. 0 autor lembra que o mapa do medo é um decalque não linear do mapa da violência. Seria possível adicionarmos ainda uma terceira camada territorial a esta trama: o mapa digital da violência?

Segundo Lesczynski (2019), “os geógrafos estão cada vez mais interessados em espacialidades que são produzidas por meio de recursos digitais,

11 Em um corpus que não está neste artigo, analisamos os relatos dos cariocas que disseram mudar trajetos e horários em função dos alertas de tiroteio.

12 Essa geografia mental não é descartada pelos geógrafos, por exemplo, como parte dos elementos definidores do espaço geográfico (Haesbaert, 2014, p. 37).

Dossiê Feminismos vitais - https://revistaecopos.eco.ufrj.br/

DOI: 10.29146/ecopos.v24i1.27624 
automatizados ou não [como é o caso da fanpage], e de como esses dispositivos interferem no cotidiano" (p. 15). Sua perspectiva sobre o conceito de espaço mediado funciona muito bem para a Comunicação, uma vez que esta pesquisa não entende mediação como intermediação, entendimento equivocado tão frequentemente observado em algumas abordagens tecnológicas. Em vez disso, Lesczynski (2019) assume a mediação como processo cultural, paradigma consagrado pela clássica via de Martín-Barbero (1997) e à qual esta pesquisa se filia, embora em diálogo com a questão tecnológica. "As tecnologias capturam, inscrevem e colocam informações em circulação de formas inéditas, formas estas que são geradoras de modos emergentes de sociabilidade e espacialidade" (Lesczynski, 2019, p. 19). Assim, a fanpage OTT-RJ não seria stricto sensu um processo de "datificação" da cidade, mas envolveria, sim, a relação entre informação digital e experiência urbana. Na OTT-RJ, não são objetos urbanos que emitem dados para a formação de um mapa autômato, mas, ainda assim, a representação de cidade que dali se pode formar é parte de um território informacional construído a partir das narrativas dos usuários.

A mediação da violência não nasce com os sites de rede social, é claro. Narrativas midiáticas sobre a violência urbana ajudam a formar um imaginário sobre a cidade há décadas. Aliás, parte do argumento usado pelos jornais e pelo público em geral para justificar a necessidade da cobertura policial, na tentativa de escapar às críticas associadas ao simples sensacionalismo, está justamente na ideia de prestação de serviço. Além de permitir a cobrança da ação por parte do poder público, saber onde um crime ocorreu supostamente levaria maior segurança ao leitor, pois ele teria ciência dos locais a serem evitados. No caso da imprensa diária, com sua periodicidade de 24 horas ou mesmo com sua versão online atualizada algumas vezes por dia, o leitor pode até imaginar um mapa da criminalidade para se orientar no trânsito pela cidade, mas estes recursos possuem agilidade limitada.

Dossiê Feminismos vitais - https://revistaecopos.eco.ufrj.br/

ISSN 2175-8689 - v. 24, n. 1, 2021

DOI: 10.29146/ecopos.v24i1.27624 
A fanpage não se equipara neste quesito ao aplicativo, mas foi uma tentativa. Como vimos em outro momento (Antunes, Matheus, 2018), os usuários afirmam, sim, mudar rotas e horários com base na avaliação de risco que fazem a partir da OTTRJ.

Para Rancière (2003), “com o enfraquecimento dos sistemas de proteção social oferecidos pelo Estado, temos uma sociedade que busca o controle dos riscos" (Rancière, Folha de São Paulo, Caderno Mais, 21/09/2003, online). No entanto, esse discurso sobre a falta de Estado pode também ser entendido como um processo de transferência da gestão de risco pelos indivíduos, em uma lógica hiper liberal (ou neoliberal). Neste sentido, a OTT-RJ pode até ser útil, mas acabaria estimulando a ideia de que o próprio cidadão é responsável por se proteger. Haesbaert (2014) denomina esse processo de contenção territorial, porém sem a necessidade do recurso de cercas e muros. A sociedade contemporânea teria como forma o "confinamento ou isolamento, mas o constrangimento e a barragem"13 (p. 156). O conceito de contenção serve para denunciar os processos de exclusão social na própria construção territorial, mas vimos que essa disputa também pode se dar por autossegregação (Souza, 2008) como no caso dos shoppings e condomínios de luxo. Nestes casos, a segurança se daria pela imobilidade. Mas, para a grande maioria da população, este isolamento simplesmente não é possível. Para este grupo, a OTT-RJ traria a sensação de maior segurança ao alertar sobre a ocorrência de tiroteios. 0 controle do espaço urbano pelo monitoramento digital (ainda que dependente de relatos individuais, como no caso da fanpage) ajuda na construção de territórios tecnológico-informacionais (Haesbaert, 2014, p. 265), que impactam a mobilidade dos cidadãos. Essas redes passam a ser verdadeiros "condensadores tecnológicos de ação, de movimento da sociedade", segundo Haesbaert (2014, p. 81).

13 Como forma de combater essas perdas experienciais, cognitivas e de cidadania, discute-se cada vez mais a tática da valorização da errância. Cf. Jacques (2012), Fernandes et al. (2019).

Dossiê Feminismos vitais - https://revistaecopos.eco.ufrj.br/

ISSN 2175-8689 - v. 24, n. 1, 2021

DOI: 10.29146/ecopos.v24i1.27624 


\section{Digitalização da violência e experiência urbana}

Acompanhando a fanpage da OTT-RJ desde sua criação, em 2016, observamos como seus usuários têm relatado a alteração na sua mobilidade na cidade $^{14}$. Frequentemente, eles afirmam ter mudado de rota e de horário para não passar pelos locais onde a OTT-RJ avisa estar havendo tiroteio. Para este artigo, realizamos um recorte temático dos posts, a partir de um acontecimento que marcou a narrativa recente sobre a violência na cidade (e no estado) do Rio de Janeiro: a intervenção de 2018. 0 corpus é composto pelas 12 publicações feitas no dia 16 de julho de 2018, quando a intervenção começou oficialmente (tabela 1).

Tabela 1: Publicações na fanpage OTT-RJ no dia 16 de fevereiro de 2018

\begin{tabular}{|c|c|c|c|}
\hline & Local & $\begin{array}{c}\text { Tipo de } \\
\text { ocorrência }\end{array}$ & Localização geográfica \\
\hline 1 & $\begin{array}{l}\text { Complexo da Coruja, em } \\
\text { São Gonçalo }\end{array}$ & Tiroteio & $\begin{array}{l}\text { São Gonçalo - município } \\
\text { vizinho }\end{array}$ \\
\hline 2 & $\begin{array}{c}\text { Rua Padre Telêmaco, em } \\
\text { Cascadura }\end{array}$ & Manifestação & Zona Norte \\
\hline 3 & $\begin{array}{l}\text { Avenida Brás de Pina, na } \\
\text { Penha }\end{array}$ & Protesto & Zona Norte \\
\hline 4 & Rua João Pessoa & Assalto & $\begin{array}{c}\text { Niterói - município } \\
\text { vizinho }\end{array}$ \\
\hline 5 & $\begin{array}{c}\text { Avenida Brasil, em Vila } \\
\text { Kennedy, em Bangu }\end{array}$ & Tiroteio & Zona Oeste \\
\hline 6 & $\begin{array}{c}\text { Bairro da Cachamorra, em } \\
\text { Campo Grande }\end{array}$ & Protesto & Zona Oeste \\
\hline 7 & $\begin{array}{c}\text { Bairro da Cachamorra, em } \\
\text { Campo Grande }\end{array}$ & Tiroteio & Zona Oeste \\
\hline 8 & $\begin{array}{c}\text { Acesso à Ponte Rio- } \\
\text { Niterói, próximo ao INTO }\end{array}$ & Arrastão & Centro \\
\hline
\end{tabular}

14 Por questão de privacidade, não identificamos os usuários que comentaram nos posts, e mantivemos os eventuais erros de português por se tratar de material empírico, cuja integridade deve ser preservada.

Dossiê Feminismos vitais - https://revistaecopos.eco.ufrj.br/

ISSN 2175-8689 - v. 24, n. 1, 2021

DOI: 10.29146/ecopos.v24i1.27624 


\begin{tabular}{|l|c|c|c|}
\hline & Local & $\begin{array}{c}\text { Tipo de } \\
\text { ocorrência }\end{array}$ & Localização geográfica \\
\hline 9 & $\begin{array}{c}\text { Bairro do Caju, próximo à } \\
\text { passarela 5 }\end{array}$ & Tiroteio & Zona Norte \\
\hline 10 & $\begin{array}{c}\text { Comunidade da Maré, em } \\
\text { Benfica }\end{array}$ & Tiroteio & Zona Norte \\
\hline 11 & $\begin{array}{c}\text { Linha Vermelha, na Ilha do } \\
\text { Governador }\end{array}$ & Arrastão & Zona Oeste \\
\hline 12 & $\begin{array}{c}\text { Avenida Geremário } \\
\text { Dantas, em Jacarepaguá }\end{array}$ & Protesto & \\
\hline
\end{tabular}

Fonte: OTT-RJ, Facebook, coleta em 17 de julho de 2018.

A escolha dos comentários a estes posts foi o critério de popularidade apontado pelo Facebook. A ordem cronológica trazia muitos comentários que continham apenas tags e não narrativas, conforme nos interessava, por isso optamos pela seleção com base no índice de popularidade à critério da própria plataforma. Como se pode observar, as ocorrências são basicamente na Zona Norte. As postagens apresentam uma cobertura geográfica da criminalidade, permitindo ao usuário elaborar uma representação mental sobre o território, especialmente ao identificar, nas fotos publicadas, os locais onde o tiroteio estava acontecendo (alguns posts continham fotografias). Isso foi possível porque os usuários indicam, nas postagens, a localização das ocorrências.

Os episódios não se restringiram apenas à cidade do Rio. Apareceram dois casos de tiroteios em municípios vizinhos: Niterói e São Gonçalo. Naquele dia, não houve nenhuma referência a tiroteios na Zona Sul, área rica da cidade, indicando que os efeitos da violência fariam parte de uma dinâmica excludente, que não atinge todas as regiões do mesmo modo.

Usuário A: Está uma zona! E ainda dizem que essa merda é cidade maravilhosa. Kkkkkkkk

Usuário B: ninguém vai poder sair de casa... que tristeza essa bagunça que está o Rio de Janeiro!

Usuária C: Bom dia. Nem ouvi!!!

(OTT-RJ, Facebook, 17 de julho de 2018, sic)

Dossiê Feminismos vitais - https://revistaecopos.eco.ufrj.br/

ISSN 2175-8689 - v. 24, n. 1, 2021

DOI: 10.29146/ecopos.v24i1.27624 
Enquanto os usuários A e B manifestam revolta com a situação, a usuária C mostra atitude blasé ("Nem ouvi!"), como forma de lidar com o cotidiano ameaçador. Por outro lado, se fosse tão blasé assim, ela não seguiria uma página sobre tiroteio. Comentar no Facebook parece aí funcionar como atividade catártica para liberar um tipo de tensão que não se resolve pragmaticamente.

Nos comentários, os usuários apontam a importância de se manterem atentos, à espera da próxima ocorrência, como forma de estarem informados e atualizados e até mesmo afastados da violência. Em um cálculo permanente de risco para quem mora no Rio, a página ofereceria mais elementos para a tomada de decisões. Como as informações são publicadas quase em tempo real, a fanpage torna a cidade um local visível e vigiado 24 horas por dia, adicionando, de certa forma, uma terceira camada - esta informacional - sobre os já sobrepostos mapas da violência e do medo. Estes dois mapas, evidentemente, já não são perfeitamente correspondentes, em um tensionamento permanente entre as ocorrências e a experiência do medo (Souza, 2008; Matheus, 2011). Acrescenta-se ao imaginário dos seguidores da página mais esta camada de medo e violência mediada pela plataforma.

Usuário D: Tia XXX15 curti essa página para ficar de olho Usuária E: XXX, veja só os posts desta página. Ta geral!! Usuária F: XXX olha só como está Usuária G: XXX na rua do XXX Será que ele é a família estão bem??? (OTT-RJ, Facebook, 17 de julho de 2018, sic)

Os quatro comentadores acima marcam pessoas conhecidas, marcadas no texto com "X" para não revelar seus nomes, entre elas, a tia do primeiro, no intuito de alertá-los sobre os tiroteios. Os comentários reverberam o clima que antecedia a Intervenção Federal e que, ou mobilizava sua demanda, ou a normalizava. Os

150 XXX é nome marcado em tag, que retiramos para garantir a privacidade dos usuários.

Dossiê Feminismos vitais - https://revistaecopos.eco.ufrj.br/

ISSN 2175-8689 - v. 24, n. 1, 2021

DOI: 10.29146/ecopos.v24i1.27624 
usuários D, E, F e G marcam (XXX) parentes e amigos para que sigam a página, na esperança de aumentar sua segurança. Nesses casos, fica clara a relação que os moradores estabelecem com a informação como instrumento de proteção, ao terem a sensação de poder monitorar a cidade. Não por acaso, os administradores da OTT-RJ se referem a seus seguidores como "família", um termo que implica uma relação de proteção e confiança. Esse tipo de iniciativa, por mais bem intencionado, justificável ou mesmo necessário que seja, inscreve-se em um processo de privatização da sociedade no mundo contemporâneo no qual até mesmo a gestão de risco público passa a ficar a cargo de indivíduos privados, no sentido da definição de esfera pública de Habermas (1984). Segundo Souza (2008), iniciativas de autossegregação - que neste caso estamos considerando como da fanpage e outras formas de monitoramento - acabam enfraquecendo o exercício da cidadania desses mesmos indivíduos autossegregados, mas não somente. Toda a sociedade passaria a fragilizar seu princípio democrático de circulação.

O prejuízo na mobilidade, por causa da violência, aparece enquanto relatos, nos boxes de comentários, indicando muros invisíveis. Nesse sentido, o monitoramento geográfico da violência impactaria a mobilidade do cidadão, mesmo ao considerarmos uma mídia não-locativa stricto sensu, como o Facebook.

Usuário $\mathrm{H}$ : XXX cada dia tá mais difícil sair de casa! Usuária I: Se eu saio às 21:00 eu tava lascada.

Usuária J: Um Estado Falido que perdeu o controle até quando vamos ser prisioneiros do medo sem direito de ir e vir. Senhor nos proteja.

Usuário K: Caveirão acabou de entrar, peguei o primeiro ônibus que eu vi! Usuária L: Meu Deus! Estamos reféns! Graças a Deus não estavam lá.

Usuário M: Sacanagem isso meu padrasto tá preso e não consegue chegar no BRT do mato alto ele pega 19:00 no trabalho na barra da tijuca

Usuária N: Ia de Ponte hoje, ainda bem que desisti! Peguei a barca! Estou ficando apavorada!

Usuária 0: XXX MEU DEUS! E eu ia vir de Coesa! Só Deus mesmo

Usuário P: Ainda bem q eu passei e n tinha isso.. olha q sai do trampo as $18: 30$

Dossiê Feminismos vitais - https://revistaecopos.eco.ufrj.br/

ISSN 2175-8689 - v. 24, n. 1, 2021

DOI: 10.29146/ecopos.v24i1.27624 
Usuário Q: Eu desci na passarela 9, tava tudo parado, aí peguei o brt na Santa Luzia e peguei o trem em Madureira

Usuário R: Porraaaaaa fiquei 6 horas nesse transito infernal, vários arrastoes

Usuário S: Foi bem n hora e eu tv chegando d mercado

Usuário T: Eu tava chegando em casa e essa hora vindo do norte shopping tudo parado, graças a Deus q peguei um táxi e vim pela Goiás

Usuário U: Tiraram nosso direito de ir e vir... covardes

(OTT-RJ, Facebook, 17 de julho de 2018, sic)

Como ilustra a coletânea de comentários acima, extraída da amostragem dos 50, parte das ocorrências dizia respeito a operações policiais, como é frequente nos episódios de tiroteios, mas, naquele dia, havia o agravante da intervenção federal. M. relata que o padrasto ficou "preso" por causa de um tiroteio, sem poder ir ao trabalho. K. diz que o "Caveirão [carro blindado] acabou de entrar, peguei o primeiro ônibus que vi”, ou seja, o morador devia estar esperando o transporte no ponto de ônibus, mas pegou outra linha para escapar da região onde havia iminência de tiroteio. N. também relata ter se livrado de um possível risco de bala perdida, ao ter evitado a Ponte [Rio-Niterói]. Chamam a atenção os relatos de alívio por se ter escapado de múltiplas situações. Em geral, os comentários na página vão nesta mesma linha, mesmo além de nossa amostra.

Esses relatos revelam os trajetos que cariocas fazem no cotidiano, seja para o tempo de lazer ou para o trabalho. Eles acabam revelando também, inadvertidamente, a dificuldade do transporte público. Nesses comentários, os usuários descrevem a quantidade de transportes que precisam pegar em uma sequência de baldeações, sempre tomando a OTT-RJ como referência em caso de precisar mudar a rota. Acompanhar esses relatos transmite uma ideia de tensão permanente, segundo a qual é preciso estar reavaliando os riscos dos trajetos o tempo todo, para, a qualquer momento, mudar a tática de circulação. A decisão sobre a Ponte Rio-Niterói ou as Barcas, ônibus ou táxi, e até a menção ao 
engarrafamento de seis horas apontam para a dificuldade de ir e vir em uma cidade cuja mobilidade é constrangida pela violência ou pelo medo.

\section{Considerações finais}

Ainda na época em que era apenas uma fanpage, a OTT-RJ se tornou fonte para os jornais locais. 0 diário carioca Extra chegou a ter uma coluna dedicada à OTT-RJ. Não raras vezes as emissoras de TV também usaram vídeos que foram originalmente publicados na fanpage. Pelos dados publicados pelos seguidores, no dia da intervenção federal, momento emblemático da insatisfação com a Segurança Pública no estado, foi possível imaginar uma geografia da violência, em uma representação mental do território urbano.

A violência tinha afetado, naquele dia, bairros das zonas Norte e Oeste do Rio, não havendo publicações sobre a Zona Sul, parte privilegiada da cidade. Esse dado parece indicar que, contrariamente à sua hiper representação pelos jornais, a Zona Sul tem menos tiroteios, enquanto o crime armado atinge mais as zonas Norte e Oeste. Além disso, as ocorrências não estavam restritas à cidade do Rio, mas às vizinhas Niterói e São Gonçalo.

A sistematização desses dados mostra, ainda, uma dialética da mobilidade que marca o espaço urbano a partir das informações de violência que são publicadas na fanpage, tanto no sentido daqueles que deixam de andar por certos locais com a privação de livre circulação quanto para aqueles que cultivam o medo justamente por acompanhar essas postagens no Facebook. A partir da criação de um mapa mental do crime, os dados apontaram ainda para uma delimitação geográfica, a partir de uma contenção - seja autossegregada ou não - na trama da cidade. Esse cerceamento da mobilidade pode ser visto quando os moradores afirmam, nas publicações, que deixam de sair de casa ou alteram a rotina, o trajeto,

Dossiê Feminismos vitais - https://revistaecopos.eco.ufrj.br/

ISSN 2175-8689 - v. 24, n. 1, 2021

DOI: 10.29146/ecopos.v24i1.27624 
o horário de circulação e até o meio de transporte por causa das informações que leram na fanpage. Essas narrativas servem como bússola para que esses indivíduos possam transitar pela cidade.

Do ponto de vista teórico, a OTT-RJ permite desdobrar a pesquisa em inúmeras problematizações que este artigo não deu conta e que merecem aprofundamento, tal como o suposto grau de "inteligência" de uma cidade por meio dessas práticas colaborativas. A despeito de todo o questionamento acerca da ideia de "smart city", o que chama atenção aqui é a necessidade, no Rio de Janeiro, de uma infraestrutura informacional que ajude o cidadão a sobreviver a riscos muito mais prementes do que simplesmente para ganhar tempo no trânsito. A estruturação informacional das cidades talvez nos leve a pensar "smart cities" de modo muito mais vital do que simplesmente em relação à necessidade de otimização do tempo. Nesse sentido, discussões importadas de países centrais parecem assumir formas e necessidades muito mais críticas em países periféricos altamente violentos.

No plano do imaginário, percebemos como a OTT-RJ, mesmo sendo uma fanpage inicialmente, e não um aplicativo com GPS, foi e é capaz de, com limitações tecnológicas, ajudar o carioca a imaginar um mapa da violência, independente tanto dos números oficiais de confrontos armados quanto da representação jornalística que tradicionalmente hiper representa a Zona Sul.

\section{Referências bibliográficas}

ANTUNES, B. F. ; MATHEUS, L. C. . Cartografia da violência no Facebook e a experiência do medo. INTERIN (UTP), v. 24, p. 242-260, 2018. DOI: https://doi.org/10.35168/19805276.UTP.interin.2019.Vol24.N1.pp242-261. Acesso em: 14 de maio de 2021. 
DECRETO 9.288. Secretaria Geral da Presidência da República, 16 de fevereiro de 2018. Disponível em: http://www.planalto.gov.br/ccivil 03/Ato20152018/2018/Decreto/D9288.htm. Acesso em: 14/05/2021.

FERNANDES, C. S.; BARROSO, F. M.; BELART, V. Cidade Ambulante: a climatologia da errância nos coletivos culturais do Rio de Janeiro. Mediação, v. 22, n. 29, p. 17-35, 2019. Disponível em: <http://www.fumec.br/revistas/mediacao/article/view/7329>. Acesso em: 15 de maio de 2021.

FOGO CRUZADO. Perguntas frequentes. Site. Disponível em: <https://fogocruzado.org.br/perguntas-frequentes/>. Acesso em: 13 de maio de 2021.

FOGO CRUZADO. Relatório 2018. Relatórios, 10 de janeiro de 2020. Site. Disponível em: https://fogocruzado.org.br/relatorio-anual-2019/. Acesso em: 14 de maio de 2021.

FOGO CRUZADO. Sobre. Site. Disponível em: https://fogocruzado.org.br/sobre/. Acesso em 13 de maio de 2021.

FRAGOSO, S; RECUERO, R; AMARAL, A. Métodos de pesquisa para Internet. Porto Alegre, RS: Sulina, 2011.

FREITAS, R. F. Para além do Rio de Janeiro: a comunicação da arquitetura estrangeira da Barra da Tijuca. Contemporânea, v. 8, n. 1, p. 132-140, 2010. Disponível em:

https://www.e-publicacoes.uerj.br/index.php/contemporanea/article/view/693. Acesso em: 15 de maio de 2021.

HABERMAS, J. Mudança estrutural da esfera pública: investigações quanto a uma categoria da sociedade burguesa. Rio de Janeiro, RJ: Tempo Brasileiro, 1984.

HAESBAERT, R. Viver no limite. Território e multi/transterritorialidade em tempos de insegurança e contenção. Rio de Janeiro, RJ: Bertrand Brasil, 2014.

ISP (Instituto de Segurança Pública). Séries históricas anuais de taxa de letalidade violenta no estado do rio de janeiro e grandes regiões. Março, 2021. Disponível em:

http://www.ispdados.ri.gov.br/Arquivos/SeriesHistoricasLetalidadeViolenta.pdf. Acesso em: 14 de maio de 2021.

JACQUES, P.B. Elogio aos errantes. Salvador, BA: SciELO-EDUFBA, 2012.

LEMOS, A. Cultura da Mobilidade. Revista Famecos, v. 16, n. 40, p. 28-35, 2009. Disponível em: <https://doi.org/10.15448/1980-3729.2009.40.6314>. Acesso em: 2 de maio. de 2019.

LESZCZYNSKI, A. Spatialities. In: ASH, J.; KITCHIN, R.; LESZCZYNSKI, A. (Org.). Digital Geographies. Los Angeles, CA: Sage, 2019. p. 19-23.

Dossiê Feminismos vitais - https://revistaecopos.eco.ufrj.br/

ISSN 2175-8689 - v. 24, n. 1, 2021

DOI: 10.29146/ecopos.v24i1.27624 
LUQUE-AYALA, A. Urban. In: ASH, J.; KITCHIN, R.; LESZCZYNSKI, A. (Org.). Digital Geographies. Los Angeles, CA: Sage, 2019. p. 24-35.

MARTÍN-BARBERO, J. Dos meios às mediações: comunicação, cultura e hegemonia. Rio de Janeiro: Editora UFRJ, 1997.

MATHEUS, L. C. Narrativas do medo: o jornalismo de sensações além do sensacionalismo. Rio de Janeiro, RJ: Mauad, 2011.

OLIVEIRA, A. L.; CASTRO, G. G. S. Smart Cities: comunicação e consumo de um futuro prescrito no espaço urbano. INTERIN, v. 24, n. 1, p. 209-225, 2019. Disponível em: $<$ https://doi.org/10.35168/1980-5276.UTP.interin.2019.Vol24.N1.pp209-225>. Acesso em: 2 de maio. de 2019.

ONDE TEM TIROTEIO (OTT). Quem somos. Site. Disponível em <https://www.ondetemtiroteio.com.br/> Acesso em 13 de maio de 2021.

ONDE TEM TIROTEIO (OTT), Facebook, comentários de 17 de julho de 2018. Disponível em <https://www.facebook.com/OTTRJ/> Acesso em: 18 de julho de 2018.

QUINTANILHA, Benito. Entrevista gentilmente concedida à Bianca Antunes por telefone em 28 de outubro de 2019.

RANCIÈRE, J. 0 princípio da insegurança. Folha de São Paulo, Caderno Mais, São Paulo, 21 set. 2003. Disponível em: <https://www1.folha.uol.com.br/fsp/mais/fs2109200303.htm>. Acesso em: 2 de maio de 2019.

RECUERO, R. Redes sociais na Internet. Porto Alegre, RS: Sulina, 2009.

ROSA, Bruno. O GLOBO é o jornal que mais cresceu em 2018. 0 Globo, 25 de janeiro de 2019, online. Disponível em: https://oglobo.globo.com/economia/o-globo-o-jornal-quemais-cresceu-em-2018-23400125. Acesso em: 14 de maio de 2021.

SOUZA, L. S. Fobópole: 0 medo generalizado e a militarização da questão urbana. Rio de Janeiro, RJ: Bertrand Brasil, 2008. 